\title{
A Remote-Sensing and GIS-Based Integrated Approach for Risk- Based Prioritization of Gold Tailings Facilities - Witwatersrand, South Africa
}

\author{
S. Chevrel Bureau de Recherches Géologiques et Minières, France \\ L. Croukamp Council for Geoscience, South Africa
}

A. Bourguignon Bureau de Recherches Géologiques et Minières, France

F. Cottard Bureau de Recherches Géologiques et Minières, France

\begin{abstract}
The Witwatersrand gold field, located in the vicinity of Johannesburg, has been mined for more than a century. The Witwatersrand Mining Basin is covered with an excess of $400 \mathrm{~km}^{2}$ of covered tailings heaps, thus affecting a considerable area and large watersheds. Tailings dams, waste rocks and derelict lands can lead to regional environmental problems and disseminate potentially toxic materials into the environment. This paper describes a collaborative project between the South African Council for Geoscience (CGS) and the French Bureau de Recherches Géologiques et Minières (BRGM) Geological Surveys, on an Earth Observation and GIS-based integrated methodology for rapid spatial screening and source characterization of hazards associated with gold slime dam features at the local to the regional scale in the Witwatersrand gold fields.

The following was performed: (i) a visual interpretation of land-use over time from satellite images, which shows the growing urbanization in the West and East Rand, as well as tailings dams-reclamation, in particular in the East Rand; (ii) a land-cover digital classification based on validated image spectra from multi-spectral ASTER imagery, with a focus on potential surface water contamination; and (iii) a simplified and Preliminary Risk Assessment (PRA), combining a number of information layers in a GIS, to rank the tailing dams waste facilities and identify the sites requiring remedial actions or water/soil usage restrictions. The GIS analysis is based on several data layers, including satellite images, digital elevation models (DEMs), topographic maps, airborne radiometric images, geotechnical maps, groundwater depths, boreholes, sinkholes and land cover. It uses a score-based ranking approach for each of the three components of the pollutant source - pathway - receptor pollutant model. The final product is presented in the form of maps that break down the final risk level related to the site, or the source classification, into three categories: (i) sites at 'high risk', corresponding to sites requiring remedial works, land-use restrictions or further detailed investigations; (ii) sites only requiring monitoring and for which it might be necessary to draw up land-use restrictions as well as investigate and monitor sites with uncertain conditions; and (iii) so-called 'low-risk' sites not requiring particular actions.
\end{abstract}

\section{Introduction}

This study made up part of a larger project carried out by the Council for Geoscience (CGS).

The initial objectives of the study were three-fold:

- Historical monitoring of land-use in the Witwatersrand through the use of time-series of TM and Advanced Spaceborne Thermal Emission and Reflection Radiometer (ASTER) satellite images.

- Monitoring pollution changes and identification of pollution details using ASTER satellite imagery.

- Risk-based land management, from a polluter-payer liability perspective, using satellite image interpretation and relevant environmental data, in GIS combination. 
The historical monitoring aims at extracting and mapping environmental management components and their evolution over time. Particular attention has been paid to land-use and land cover features, in other words surface water, slime dams, mining infrastructures, vegetation, urban expansion, industrial areas, agriculture, and pollution pathways.

All available ASTER data have been used for firstly monitoring pollution changes over time and identifying pollution details, including tailings dissemination and surface water contamination.

The risk-based land management, and relevant liability study aims at producing preliminary risk-assessment and risk management maps from the results of historical monitoring, and monitoring pollution studies, through GIS combinations. The objective is the preparation of preliminary documents aiming at answering questions surrounding lands contaminated as a result of mining-related activities and their actual or future use, such as, who is responsible and liable for what? Who is really at risk? What kind of appropriate action can be proposed in terms of risk reduction and sustainable land management?

The work performed comprised:

- Land-use interpretation of 1989 (Landsat) and 2003 (ASTER) satellite images.

- GIS combinations including pollution sources located in flooding areas and inhabited areas located within $500 \mathrm{~m}$ of a pollution source.

- Classification of land-use, and in particular surface waters and silica-tailings, from ASTER data set (2000 and 2003) to study relationships between the presence of tailings and water contamination.

- Ranking of 80 sites based on a preliminary risk assessment (PRA) methodology.

The Witwatersrand mining basin is composed of several distinct mining areas (Figure 1) namely the Far East Rand Basin, Central Rand Basin, Western Basin, Far Western Basin, Klerksdorp (KOSH) area and the Free State gold fields, and includes in excess of $400 \mathrm{~km}^{2}$ of gold mine deposits, thus affecting a considerable area and large watersheds. The names used in this study are the old (pre-1990) names of mining areas that are still in common use, i.e. West Rand (including Western and Far-Western areas), Central Rand and East Rand.

The Witwatersrand has been mined for more than a century. It is the world's largest gold and uranium mining basin with the extraction, from more than 120 mines, of 43,500 tons of gold in one century and 73,000 tons of uranium between 1953 and 1995 (Wilson and Anhaeusser, 1998). The basin covers an area of $1600 \mathrm{~km}^{2}$, and led to a legacy of some $400 \mathrm{~km}^{2}$ of mine tailings dams (Robb and Robb, 1998) and 6 billion tons of pyrite tailings containing low-grade uranium (U) (Wymer, 2001).

It is recognized that gold and uranium tailings dams, waste rocks and derelict lands have the potential to cause severe environmental damage, which includes acid mine drainage, and the dissemination of metals, naturally-occurring radionuclides (NORMs), and process reagents, such as cyanide, into the environment (Winde, 2006). Starting in the mid-1980s, many tailings dams in the Witwatersrand region have been, and are still being, reprocessed using a cyanide process for residual gold extraction. 


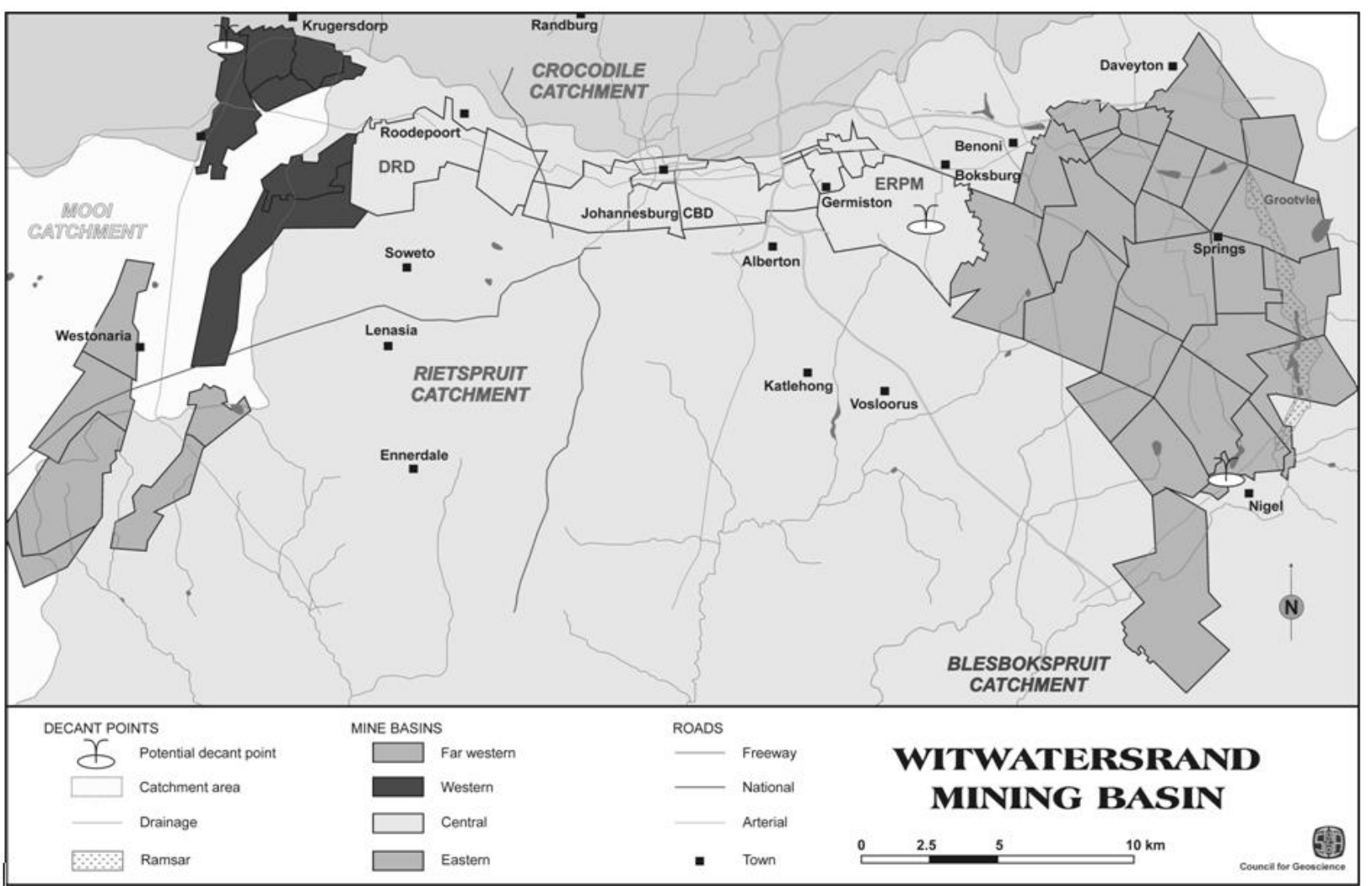

\section{Figure 1 The Witwatersrand gold fields}

\section{Data sets}

The following data were made available to the study:

- Landsat TM time series: dry and wet seasons for the years 1985, 1989, 1992, 1995, 1998, 2001 and a mosaic of spring 2001 - 2002 Landsat 7 images, bought through the United States Geological Survey (USGS) EROS data centre.

- ASTER data set: spring (September and October) 2000 covering the Central and East Rands; March 2003 covering the East Rand; October 2003 covering Central Rand and April 2001 covering Far West Rand, brought through the USGS EROS data centre.

- Topographic maps (raster), provided by the Council for Geoscience (GCS) of South Africa.

- Digital elevation models (DEMs): shuttle radar topographic mission (SRTM) coverage of the whole area and a $10 \mathrm{~m}$ DEM covering the Central Rand, provided by the CGS.

- Vector files: topographic maps, geological maps, geotechnical maps, surface mine works, sinkholes, water levels, boreholes as well as soils and land types, provided by the CGS.

- Very high-resolution airborne geophysics (partial coverage of the West Rand), provided by the CGS.

\section{Methodology}

\subsection{Preliminary risk assessment}

The preliminary risk assessment (PRA) objective was to provide the elements for ranking (scoring) sites that present no menace to human health and the environment, and can be used without any particular action, and sites that might generate significant and lasting nuisance. PRA uses voluntarily-simple options. It is a simple scoring method modified from the french simplified risk assessment (SRA) approach to contaminated-land 
management, which served as a basis for the European Preliminary Risk Assessment Method (PRAM-MS method) of the European Environmental Agency (Gentile et al., 2005). It is based on the principle that the existence of a risk implies the related presence of: i) a dangerous/hazardous source (S), ii) a transfer mode to and from the transfer medium (Pathway: P), and iii) a target or receptor (R).

Risk assessment for contaminated lands is based on the classical source - pathway - receptor paradigm (S-P$\mathrm{R})$. There must be a source of potentially-harmful material in sufficient concentrations to pose a significant potential risk to people or the environment. There must be also a pathway linking the harmful material with the receptors at risk (e.g. humans, livestock, and important resources such as clean soil or groundwater). If any of these elements (source, pathway or receptor) are absent or removed, the site poses no risk. This philosophy provides the basis for various risk management options such as source removal, elimination of an exposure pathway by capping a site, or changing the use of the site (see Figure 2).

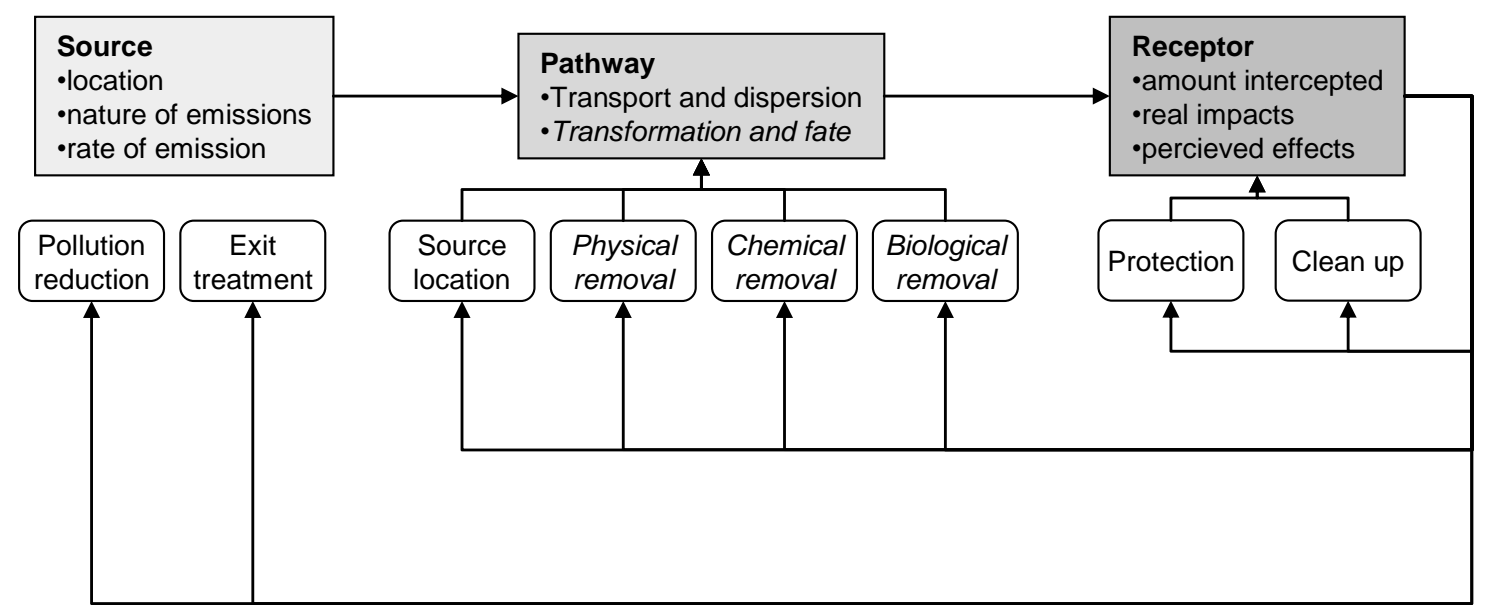

Figure 2 The Source - Pathway - Receptor paradigm of environmental transport and fate (modified after Chusman-Roisin, undated)

The scoring methodology relies on 17 parameters in four evaluation grids, coupled with a GIS, that is:

- Potential hazard of the source.

- Potential mobilization from the source toward the milieu.

- Pathways or transfer potential within the milieu towards the receptor.

- Receptor.

Each parameter is given a score from 0 to 3, with 3 being the most unfavorable situation. When information about the parameter is doubtful, an uncertainty factor is attributed. Notation and the relevant threshold are selected according to local expertise. The score is then calculated for the source itself and by pathway (groundwater, surface water and soil) versus inhalation/direct contact.

For this preliminary study, only simple options have been considered with respect to the local conditions, i.e. primary exposure targets, or receptors, are humans and water resources, only easily-accessible data is used, only primary sources (tailings and mining facilities) are considered, and a complex site is considered as the sum of single sites. The final scoring is given in three classes, which corresponds to the actions to be undertaken, i.e. class 1 corresponding to sites requiring further investigations, and emergency responses, class 2 to sites which must be monitored, and class 3 represents low-risk sites that do not need specific work (except possible restriction on urban development).

The 17 parameters correspond to:

- Source parameters: potential toxicity and concentration, residual sulphides, NORMs, quantity of tailings, physical state (stability), type of containment versus wind erosion, water and soil.

- Pathway parameters: depth to groundwater, soil permeability, aquifer permeability, distance to the closest surface water. 
- Receptor parameters: access to site/source, site environment (land-use), use of water for drinking or irrigation (groundwater and surface water).

A dedicated Excel file was prepared for input, into a single spreadsheet, in the form of notes relevant to the parameters (including uncertainty when necessary) as well as possible comments (see Figure 3). One file is used for each of the sites (or group of sites). The Excel file automatically scores, in separate spreadsheets, the site class for the source itself and each of the pathways, i.e. groundwater, surface water, and soil. A final spreadsheet summarizes the final score for the site (see Figure 4, sheet PRA), and the score for groundwater, surface water and soils.

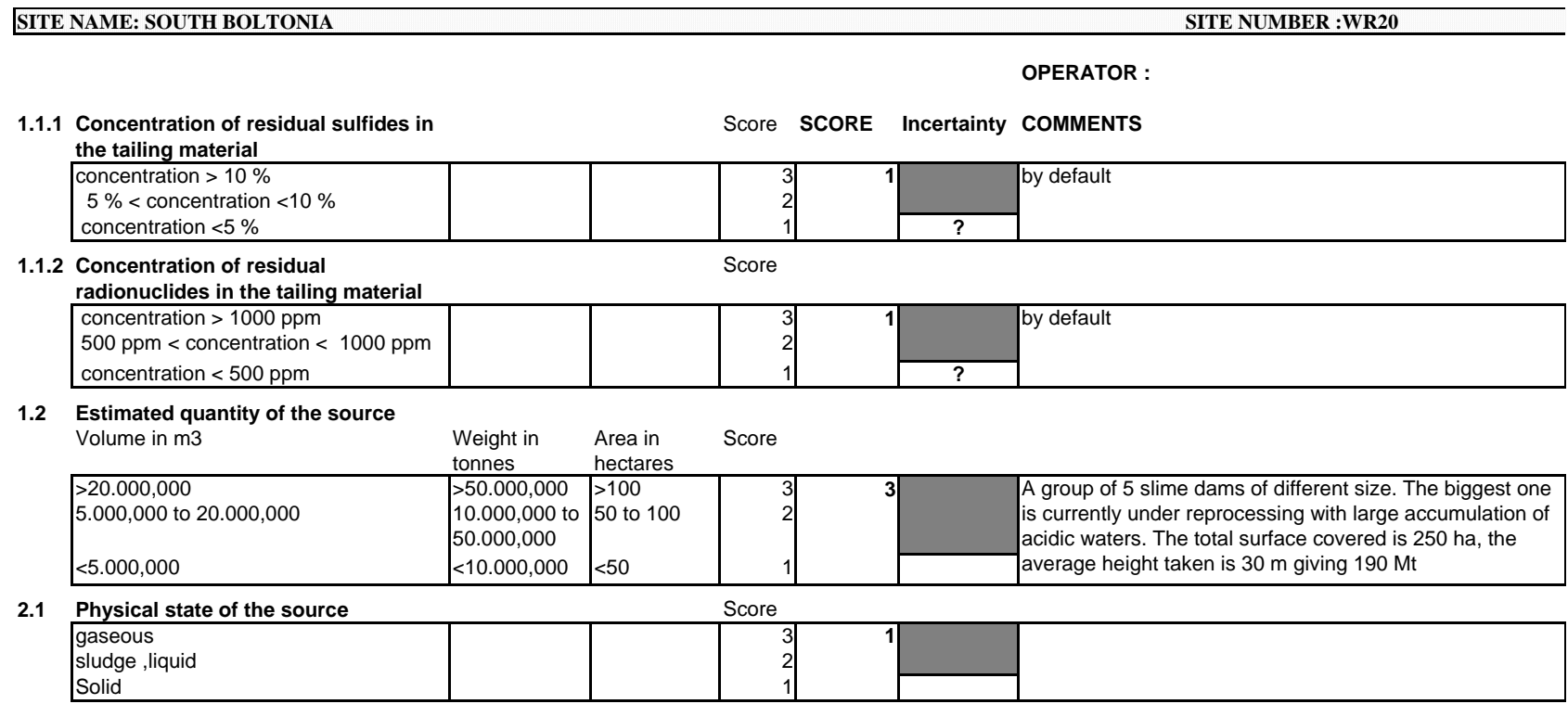

Figure 3 Extract of the data PRA Excel spreadsheet used for entering data

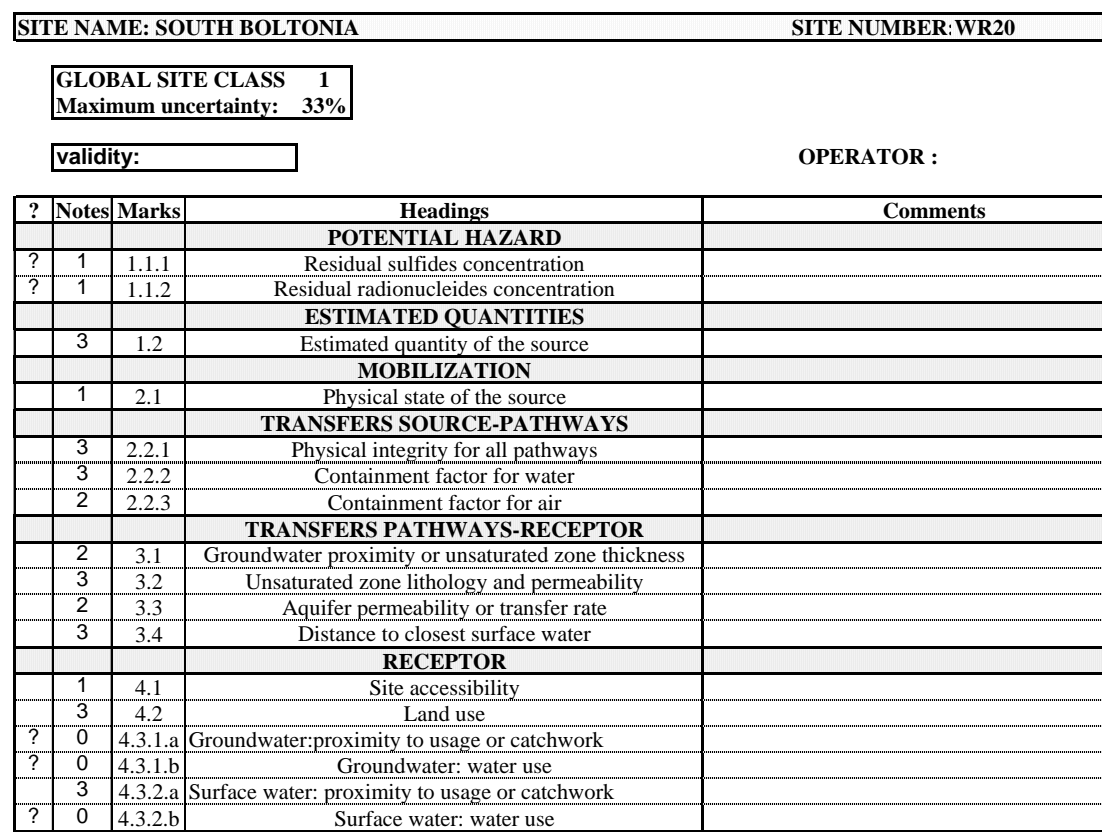

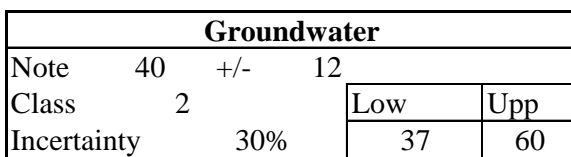

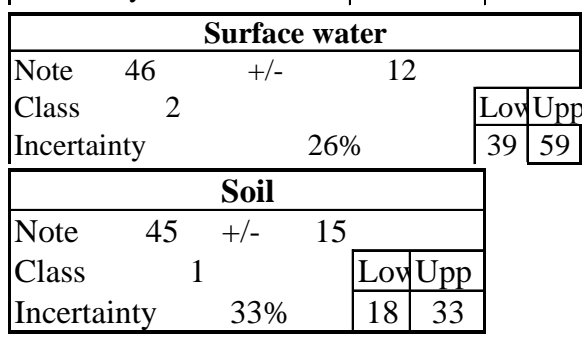

\section{Figure 4 Final PRA scoring spreadsheet}

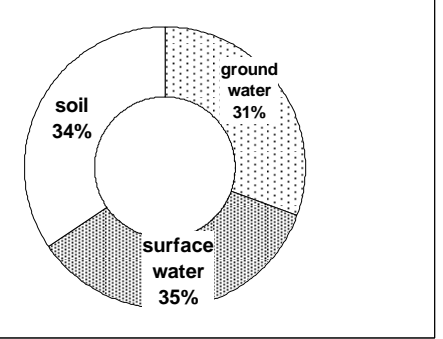




\subsection{Historical monitoring of land-use changes}

The historical monitoring of land-use in the Witwatersrand is simply based on a visual interpretation of time series of TM and ASTER satellite images. A 1989 Landsat image was used as a reference land-use image, as most tailings dam reprocessing for residual gold extraction only started after 1989.

Image interpretation was carried out using a typology based on the S-P-R concept (Table 1).

Visual interpretation is digitized and documented (polygon labeling), to be introduced into the GIS in the form of a vector layer. Land-use evolution (pre- and post-1989) can then be easily measured though digitization (polygon modification, addition, suppression) by comparison with the 1989 reference interpretation.

Table 1 Typology for image interpretation with respect to the S-P-R concept

\begin{tabular}{|c|c|c|c|}
\hline \multicolumn{4}{|c|}{ Pollution Sources (S) } \\
\hline \multirow{2}{*}{ Stu } & \multirow{2}{*}{$\begin{array}{l}\text { Stud } \\
\text { Stuw }\end{array}$} & \multirow{2}{*}{$\begin{array}{l}\text { Tailing dam } \\
\text { uncovered }\end{array}$} & \multirow{2}{*}{$\begin{array}{l}\text { Tailing dam uncovered, dry } \\
\text { Tailing dam uncovered, humid }\end{array}$} \\
\hline & & & \\
\hline \multirow{3}{*}{ Stc } & Stcv & \multirow{3}{*}{$\begin{array}{l}\text { Tailing dam } \\
\text { covered }\end{array}$} & Tailing dam covered by vegetation \\
\hline & Stcw & & Tailing dam covered by water \\
\hline & Stcr & & Tailing dam covered by waste rocks \\
\hline \multicolumn{2}{|c|}{ Std } & \multicolumn{2}{|l|}{ Tailings dispersed } \\
\hline \multicolumn{2}{|c|}{ Stt } & \multicolumn{2}{|c|}{ Tailings transported by the drainage } \\
\hline \multicolumn{2}{|c|}{ Ses } & \multicolumn{2}{|c|}{$\begin{array}{l}\text { Soils covered by tailings after re-treatment (former tailing } \\
\text { dam) even if revegetation took place }\end{array}$} \\
\hline \multicolumn{2}{|c|}{ Scw } & \multicolumn{2}{|c|}{ Contaminated waters } \\
\hline \multicolumn{2}{|c|}{ Smw } & \multicolumn{2}{|l|}{ Mine waters } \\
\hline \multicolumn{2}{|c|}{ Swr } & \multicolumn{2}{|l|}{ Waste rocks } \\
\hline \multicolumn{2}{|c|}{ Smf } & \multicolumn{2}{|l|}{ Mining facilities } \\
\hline \multicolumn{2}{|c|}{ Sd } & \multicolumn{2}{|l|}{ Diggings } \\
\hline \multicolumn{4}{|c|}{ Exposed Pathways (P) } \\
\hline \multicolumn{2}{|c|}{ Pr } & \multicolumn{2}{|l|}{ Rivers or streams } \\
\hline \multicolumn{2}{|c|}{ Pc } & \multicolumn{2}{|l|}{ Channels } \\
\hline \multicolumn{2}{|c|}{ PI } & \multicolumn{2}{|l|}{ Lakes or pans } \\
\hline \multicolumn{2}{|c|}{$\mathbf{P w}$} & \multicolumn{2}{|l|}{ Wetlands } \\
\hline & & \multicolumn{2}{|c|}{ Exposed Receptors and Targets $(R)$} \\
\hline & Riu & & Urbanized areas \\
\hline $\mathbf{D i}$ & Rir & Inhohited areos & Residential areas \\
\hline $\mathbf{M}$ & Rit & Hitravited aleas & Townships \\
\hline & Rii & & Industrial areas \\
\hline & Rrg & & Golf courses \\
\hline $\mathbf{R r}$ & Rrp & Recreational areas & Parks \\
\hline & Rrf & & Forest \\
\hline $\mathbf{R a}$ & Rac & Cultivated areas & Cultivated areas \\
\hline & $\mathbf{v}$ & Veld & \\
\hline
\end{tabular}




\subsection{Image classification}

A land-use image classification was performed on the ASTER imagery, as well as a classification of silica tailings. Images were atmospherically corrected using built-in ENVI software routines (internal average relative reflectance for VNIR and SWIR bands, thermal atmospheric correction, followed by emissivity normalization for the thermal infrared bands).

\subsubsection{Land-use classification}

A semi-automated land-use classification was performed (Spectral Angle Mapper) using a dedicated spectral library, built of image spectra obtained from hyperspectral end-member extraction techniques (NDvisualization techniques (Boardman et al., 1994) and Pixel Purity Index (Boardman et al., 1995). Twenty-six average spectra, representative of tailings, vegetation, waters (including mine waters and contaminated waters), wetlands and grasslands were obtained this way (Chevrel, 2004).

\subsubsection{Silica tailings classification}

Thermal bands of ASTER imagery were processed using band ratios B11/(B10 + B12), B11/B10 and B13/B12 (after Cudahy, 2002) to produce a silica abundance image. It was followed by a parallelepiped classification of this newly produced image, using training areas, to lead to the production of a map of silica tailings dams.

\section{Results}

\subsection{GIS layers derived from visual image interpretation}

\subsubsection{Land-use change detection from visual image interpretation and GIS analysis}

Land-use change detection analysis, between 1989 and 2003, obtained from visual interpretation, allowed the development of mining activity over this period in the West and Far West Rand to be mapped, as well as the expansion of tailings dams reclamation in the East Rand, and rapid urbanization in the region (Soweto, Krugersdorp, East Rand) for example residential areas, formal townships and informal settlements.

\subsubsection{Pollution sources located in flooding areas}

Combining pollution sources extracted from the visual interpretation of the 2003 image, with flooding areas extracted from the geotechnical maps, made it possible to map which pollution sources (mostly tailings dams and mining facilities) were located in flooding-prone areas. The map shows that a large part of pollution sources are prone to flooding.

\subsubsection{Inhabited areas located within $500 \mathrm{~m}$ from a pollution source}

The 2003 map of inhabited areas shows that an average of 9\%, on the Witwatersrand Basin is located within $500 \mathrm{~m}$ of a pollution source, which is not in keeping with local guidelines. A breakdown indicates $18 \%$ in the West Rand, $12 \%$ in the East Rand and 25\% in the Central Rand.

\subsection{Thematic maps derived from ASTER image digital classification}

\subsubsection{Land-use classification}

The ASTER image classification, obtained from the 26 spectra described in Section 3.3.1, provided an accurate classification of tailings dams and contamination by tailings, despite unexplained confusion with industrial area roofs. A good classification of the extent of grassland enabled differentiation between grassland (on lateritic soils) and retention cells (toe-paddocks) surrounding tailings dams, covered with iron oxide and partly vegetated.

Confusion between tailings dams and industrial building roofs might be explained either by a thin tailings dust covering the roofs or by paint pigments with a similar reflectance. 
Most important is a classification of different types of surface waters, i.e. shallow waters, potentially contaminated mine waters, and red acid waters.

\subsubsection{Silica tailings classification}

Thermal band ratios (see Section 3.3.2), followed by parallelepiped classification, provide an accurate map of silica tailings extension. Two classes of silica tailings have been differentiated that suggest differences in tailings composition, compaction or wetness. Note that only uncovered tailings dams can be identified this way and that the $90 \mathrm{~m}$ ground resolution of ASTER thermal bands precludes identification of the smallest dams (or uncovered parts of dams).

\subsubsection{Contaminated waters potentially related to the proximity of tailings sources}

Merging silica tailings classification and water classification, from ASTER imagery, shows evidence of potential water contamination, which could be related to mining activities. Seventy-nine points that have a high probability of tailings contamination, as indicated by the presence of silica tailings, have been thus identified, together with their relevant geographic coordinates. Figure 5 shows such points identified, northeast of Soweto in the central Rand (highlighted by white arrows on left side, and grey dots on right side). Tailings dams are represented in black or white shades.
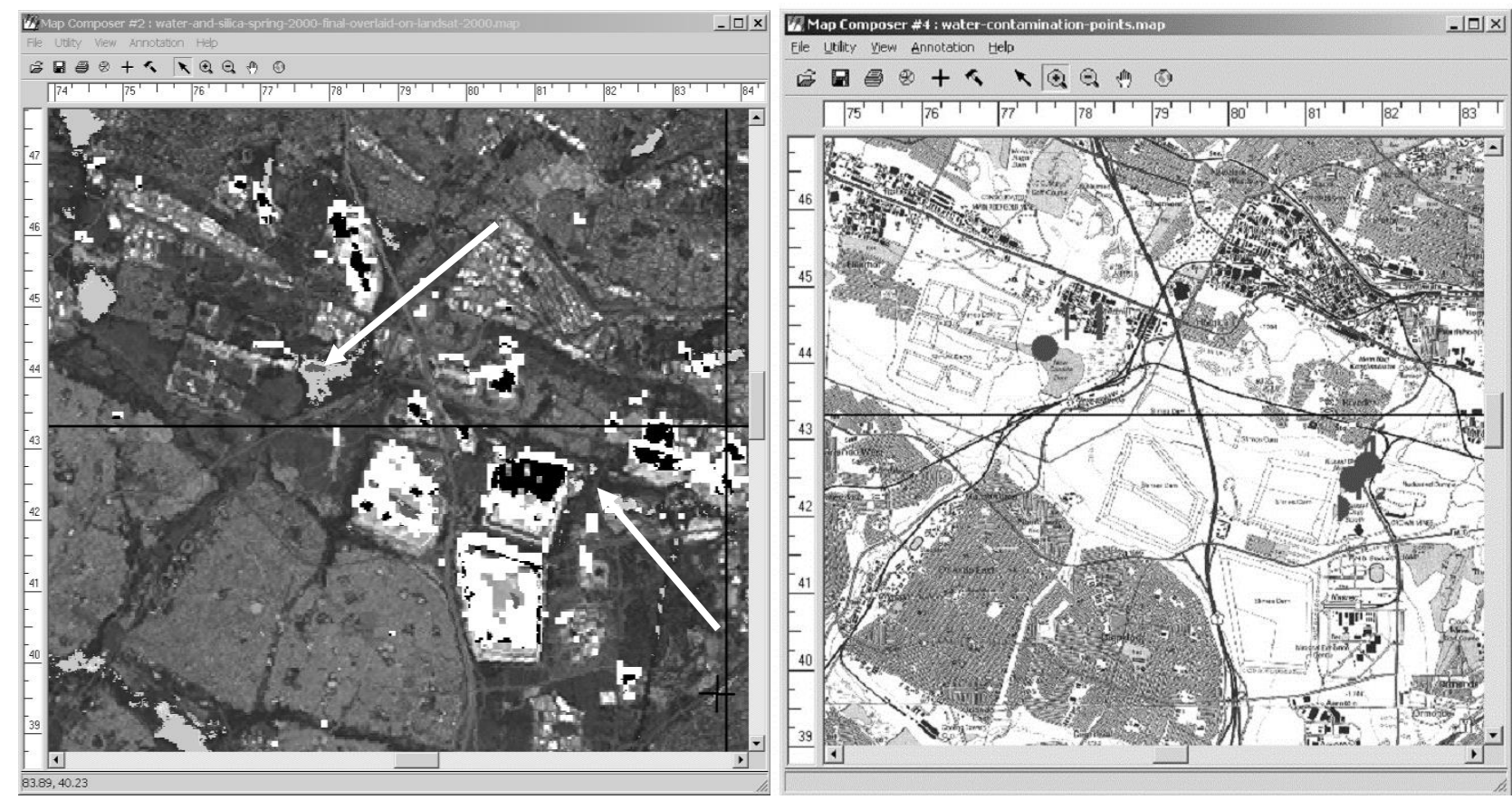

Figure 5 Merged silica tailings classification and water classification

\subsection{Soil and wetland contamination mapping}

The higher concentration of uranium in the tailings (in comparison with the local soils) makes possible the mapping of tailings contamination plumes on soils and wetlands surrounding tailings dams. An elevated uranium/thorium ratio indicates NORMs of anthropogenic origin compared to natural background level (Chevrel and Coetzee, 2000; Coetzee, 2008).

Figure 6 illustrates areas with elevated uranium/thorium ratios (uranium-related radioactivity), combined with tailings dams and drainage systems. It clearly shows the extent of soil, drainage line and wetland contamination surrounding the tailings dam facilities in the West Rand (the lack of radiometric information over Soweto is due to flight-clearance restriction over urbanized areas). Airborne radiometrics hence provides useful information on the spatial extent of contamination, but not on the chemistry (Coetzee, 2008). It is worth mentioning that the use of airborne hyperspectral mapping could be useful to detect and map the 
nature of some mineral and organic contaminants both qualitatively and quantitatively, including acid mine drainage-generating material.

\subsection{PRA analysis and scoring}

\subsubsection{Examples of parameters extraction}

All the parameters mentioned in Section 3.1 are extracted from GIS layers and/or their combination with image interpretation. The tailings tonnage is estimated from DEMs and satellite image land-use interpretation. The physical state of tailings dams is evaluated through visual examination of their distribution in relation to seepage and drainage, as well as tailings containment (covered, partially covered, uncovered and reclaimed tailings dams - see Table 1).

The thickness of the vadoze zone is extracted from geotechnical maps and groundwater table data, while soil permeability is derived from both the geotechnical map, as well as the soil and land type map (average clay content). Aquifer permeability is obtained by coding geological maps according to local expertise. Receptors are all extracted from the visual interpretation of the 2003 satellite image (see Table 1).

\subsubsection{The PRA final notation and visual presentation}

As mentioned before, each site (or group of sites) receives a final score (class 1 to 3 ) and a note for each pathway, i.e. surface water, groundwater and soils, all automatically calculated from the Excel spreadsheet described in 3.1.

Figure 7 represents a class 1 (high-risk site), presenting a low to medium risk for groundwater, medium risk for surface water and high risk for soils. The bottom bar diagrams represent the final scores for groundwater, surface water and soils, while the circle diagram represents the risk in terms of the percentage for the same three pathways. The bar chart representation on the image shows the risk for groundwater in dark grey, risk for surface water in light grey and risk for soils in medium grey.

The final results are presented in form of a map, and part of the East Rand is presented in Figure 8. The final map represents the extent of tailings dams, each color-coded according to its given class of risk. A bar chart for each of the pathways is assigned to the tailings facility (or group of sites).

\subsubsection{Final results}

A total of eighty gold and uranium mine tailings dams (or group of dams) has been ranked according to the previously described methodology (Table 2).

Table 2 Final PRA results for the Witwatersrand basin

\begin{tabular}{lcccc}
\hline & 'Class 1' Sites & 'Class 2' Sites & 'Class 3' Sites & Total No. of Sites \\
\hline West Rand & 8 & 11 & 2 & 21 \\
Central Rand & 16 & 8 & 0 & 24 \\
East Rand & 13 & 15 & 7 & 35 \\
Total Witwatersrand & 37 & 34 & 9 & 80 \\
\hline
\end{tabular}

The Central Rand, which is highly urbanized and where mineral exploitation started over a century ago, presents the highest level of risk. Low urbanization levels explain the lower level of risk in the West Rand, while the East Rand has higher risk levels due to rapid urbanization and agricultural development in an area largely occupied by extensive tailings facilities. 


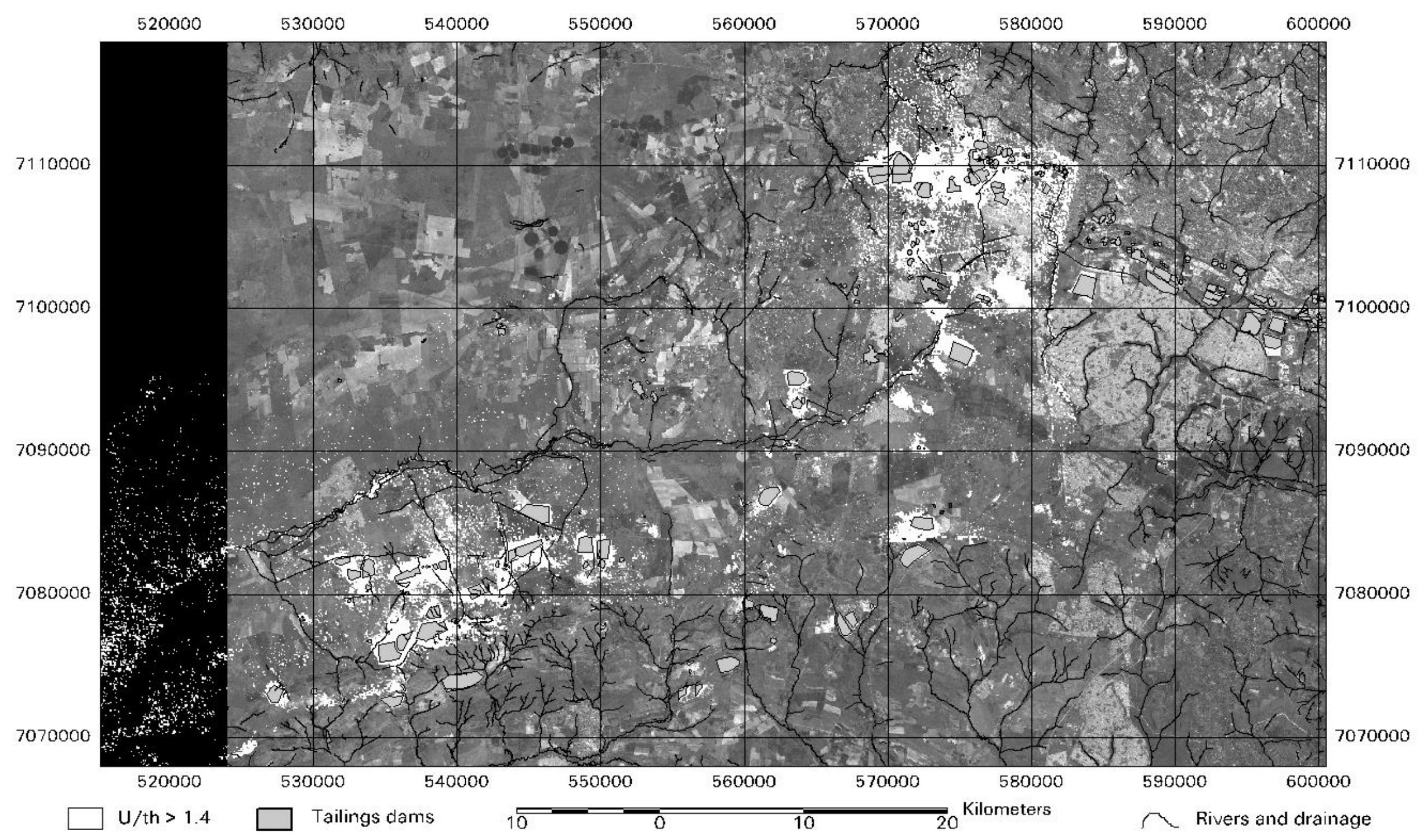

Figure 6 Image of the Far West and West Rands indicating the extent of contaminated soils and wetlands around tailings dams by an elevated (> 1.4) uranium/thorium ratio. The lack of radiometric information over Soweto is due to flight-clearance restriction over urbanized areas 

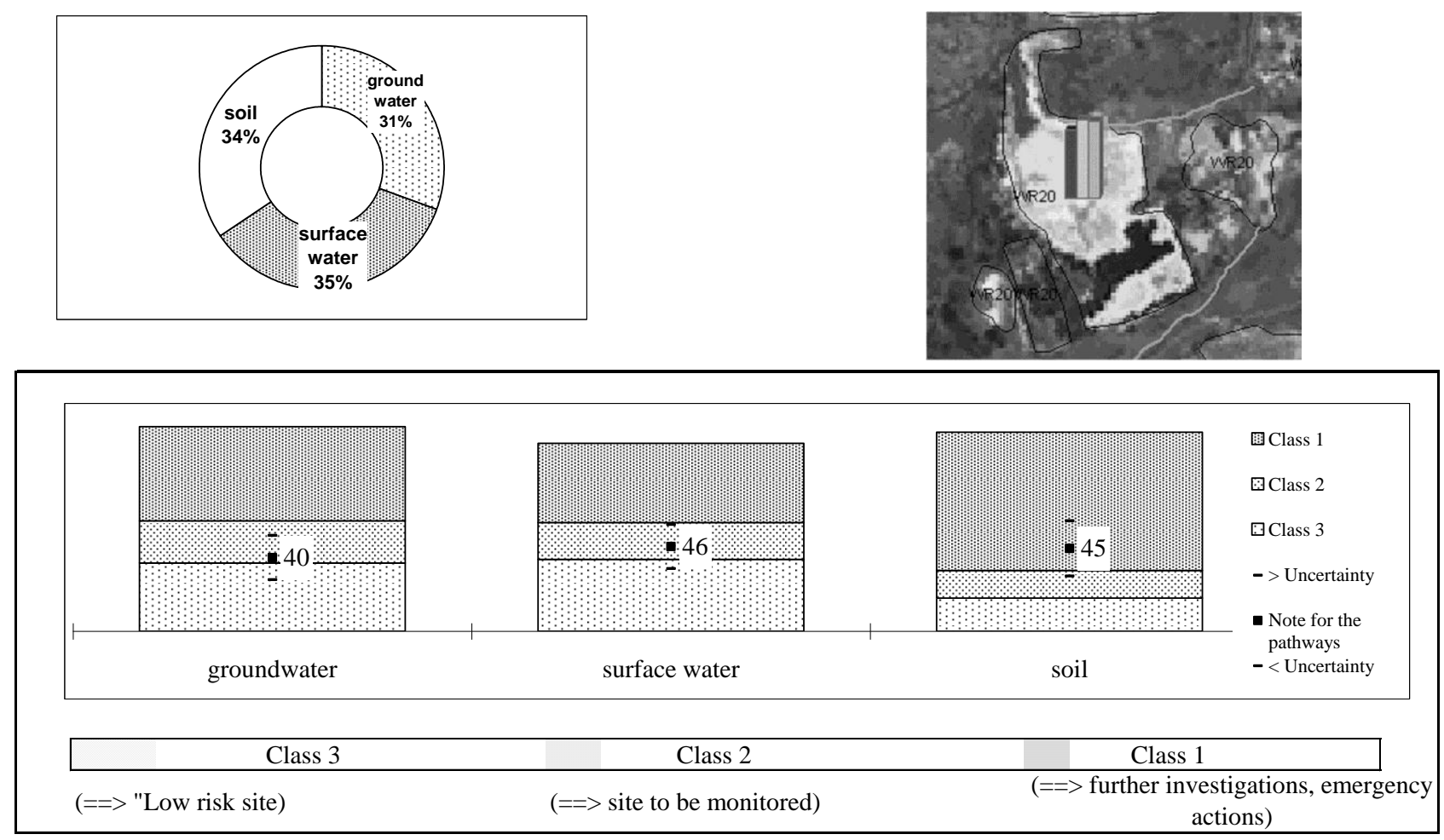

Figure 7 Final site scoring and note for each pathway, together with visual bar chart representation of the results

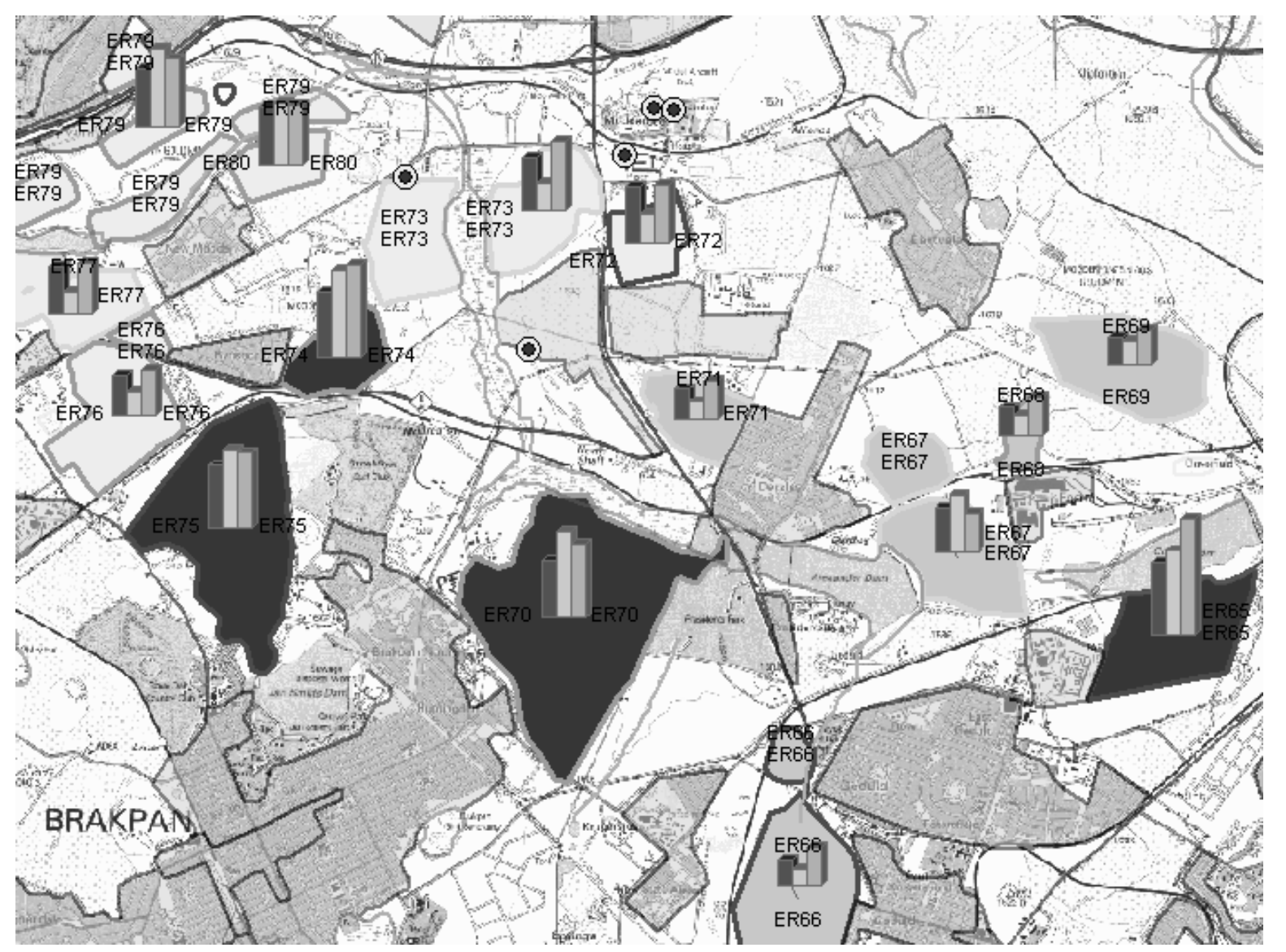

Figure 8 Tailings dam site risk ranking map for a section of the East Rand. High-risk sites (class 1) are in dark grey, medium risk in light grey and low risk (class 3) in medium grey 


\section{Conclusions and recommendations}

A preliminary risk assessment methodology has been used here, based on data made available to the project as well as local expertise. It has proven efficient in prioritizing risk associated to tailings dams facilities, over the whole mining basin. Ground-truthing must be used to complement this approach and verify the rankings.

It could be worthwhile to refine this PRA ranking and alleviate uncertainty, in particular with data on source composition and on water uses, that, due to lack of reliable data, have not been taken into account in this study. The undertaking of a second phase of the study is recommended, by focusing on class 1 sites (hot spots), in particular in the Central Rand. This could be done by acquiring field data (e.g. in the form of a rapid field visit with a checklist) in view of detailing the ranking process, site by site, e.g. presence of barriers, ditches and the like; chemical and mineral composition of the tailings; physical and chemical stability of the facilities and modes of containment. This could lead to the design of cost-effective actions for controlling the risks.

An assessment, characterization and mapping of contamination plumes from an airborne hyperspectral survey, coupled with ground-truthing and GIS analysis, would help in a better understanding of the contaminants' chemistry in the environment.

\section{Acknowledgements}

This collaborative study has been carried out by BRGM and CGS, BRGM being under commercial contract with CGS. It partly relies on the application of former developments undertaken under research and technological scientific collaboration, self funded by both parties.

\section{References}

Boardman, J.W., Kruse, F.A. and Green, R.O. (1995) Mapping target signatures via partial unmixing of AVIRIS data: in Summaries, Fifth JPL Airborne Earth Science Workshop, JPL Publication 95-1, 1, pp. 23-26.

Boardman, J.W. and Kruse, F.A. (1994) Automated spectral analysis: A geologic example using AVIRIS data, north Grapevine Mountains, Nevada in Proceedings, 10th Thematic Conference on Geologic Remote Sensing, Environmental Research Institute of Michigan, Ann Arbor, MI, pp. I407-I418.

Chevrel, S. (2004) Contribution of very high spatial and/or spectral resolution remote sensing in GIS-based environmental hazard assessment of mining environments, keynote presentation at the 12th Australasian Remote Sensing and Photogrammetry Conference, 18-22 October 2004, Fremantle, Australia (CD-ROM).

Chevrel, S. and Coetzee, H. (2000) A new tool for assessing the environmental impact of mining activities. Application to the surface and groundwater sensitivity analysis of the West Rand area, Gauteng, South Africa. Proceedings (CD-ROM) of the 28th International Symposium on Remote Sensing of Environment, Cape Town, South Africa, 27-31 March 2000, Paper RN 5.12.

Coetzee, H. (2008) Acquisition, processing and enhancement of multi-channel radiometric data collected with ultralight aircraft mounted detectors. University of the Witwatersrand, Johannesburg. PhD Thesis, 357 p.

Cudahy, T. (2002) Mapping the Earth with ASTER, ASTER Workshop, Annual Meeting of the Geological Remote Sensing Group, London, December 2002.

Cushman-Roisin, B. (undated) Environmental Fluid Mechanics, Thayer School of Engineering, Dartmouth College Hanover, New Hampshire 03755, http://thayer.dartmouth.edu/ cushman/books/EFM/chap1.pdf.

Gentile, A.R., Quercia, F., Vecchio, A., Falconi, M., Schamann, M., Tarvainen, T. and Fons, J. (2005) Towards an EEA Europe-wide assessment of areas under risk for soil contamination, Volume V. Objectives and Methodology, European Environment Agency, 23 p. (http://eea.eionet.europa.eu/Public/irc/eionet-circle/te/library?l=/ collection_2006/prams2_060703pdf/_EN_1.0_\&a=d).

Robb, L.J. and Robb, V.M. (1998) Gold in the Witwatersrand Basin. The Mineral Resources of South Africa, sixth edition, M. Wilson and C. Anhaeusser (eds), Pretoria, Council for Geoscience, pp. 294-349.

Wilson, M.G.C. and Anhaeusser, C.R. (eds) (1998) The Mineral Resources of South Africa: Handbook, Council for Geoscience, 16, $740 \mathrm{p}$.

Winde, F. (2006) Impacts of gold-mining activities on water availability and quality in the Wonderfonteinspruit catchment. An assessment of sources, pathways, mechanisms and risks of current and potential future pollution of water and sediments in gold-mining areas of the Wonderfonteinspruit catchment, H. Coetzee. Pretoria, Water Research Commission, pp. 13-34.

Wymer, D.G. (2001) The impact of gold mining on radioactivity in water and foodstuffs. Conference on environmentally responsible mining in South Africa. Chamber of Mines of South Africa. Muldersdrift, 1, pp. 2C19-2C30. 